\title{
Mitochondrial Genome Variation and Evolutionary History of Australian and New Guinean Aborigines
}

\author{
Max Ingman ${ }^{1}$ and Ulf Gyllensten \\ Department of Genetics and Pathology, Section of Medical Genetics, Rudbeck Laboratory, University of Uppsala, \\ S-751 85 Uppsala, Sweden
}

\begin{abstract}
To study the evolutionary history of the Australian and New Guinean indigenous peoples, we analyzed 101 complete mitochondrial genomes including populations from Australia and New Guinea as well as from Africa, India, Europe, Asia, Melanesia, and Polynesia. The genetic diversity of the Australian mitochondrial sequences is remarkably high and is similar to that found across Asia. This is in contrast to the pattern seen in previously described Y-chromosome data where an Australia-specific haplotype was found at high frequency. The mitochondrial genome data indicate that Australia was colonized between 40 and 70 thousand years ago, either by a single migration from a heterogeneous source population or by multiple movements of smaller groups occurring over a period of time. Some Australian and New Guinea sequences form clades, suggesting the possibility of a joint colonization and/or admixture between the two regions.
\end{abstract}

[The sequence data from this study have been submitted to GenBank under accession nos. AY289051AY289102. The following individuals kindly provided reagents, samples, or unpublished information as indicated in the paper: M. Stoneking and J. Kuhl.]

\begin{abstract}
The continent of Australia has been separate from Asia since the late Cretaceous, approximately 70 million years ago. However, lower sea levels during the upper Pleistocene merged the Malay Peninsula with Sumatra, Java, Borneo, and Bali to form what is generally known as "Sunda Land". At the same time, mainland Australia, Tasmania, and New Guinea were joined into a single landmass, called "Sahul Land" (Fig. 1). Although Sunda and Sahul have remained separate during the period of modern human evolution and migration, sea distances connecting them would have been reduced to several island hops of between 30 and $90 \mathrm{~km}$ (Klein 1989). Because Australia and New Guinea were joined from before the time of human colonization until about 8000 years ago (Bellwood 1978a), it is possible that the indigenous peoples of these regions result from the same migration. A date for initial human settlement of the Australian continent of 10,000 years ago was defendable as recently as the mid-1960s (Klein 1989). Through the re-dating of the Lake Mungo skeletal remains (Thorne et al. 1999; Bowler et al. 2003) and as a result of several other studies (Roberts et al. 1990, 1994, 2001), a date of 40,000-60,000 years ago is now generally accepted. The only estimate of a genetic coalescent for Australian Aborigines with individuals from outside Australia is based on mitochondrial HVS1 sequences and ranges from 60,000-119,000 years ago, depending on which substitution rate is used (van Holst Pellekaan et al. 1998). In addition, an expansion date of 51,000-85,000 years ago for Australian Aborigines was estimated from mitochondrial D-loop sequences (Redd and Stoneking 1999). Mitochondrial DNA has proven to be a useful tool in studying
\end{abstract}

'Corresponding author.

E-MAIL max.ingman@genpat.uu.se; FAX 46 (18) 471-4931. Article and publication are at http://www.genome.org/cgi/doi/10.1101/ gr.686603. the evolutionary history of human populations through key characteristics such as high copy number, lack of recombination (Olivio et al. 1983; Ingman et al. 2000), high substitution rate (Brown et al. 1979), and maternal mode of inheritance (Giles et al. 1980). Although the mitochondrial D-loop offers a convenient source of polymorphic data, it also has a high incidence of parallel mutations (Tamura and Nei 1993; Ingman and Gyllensten 2001) and mutation "hotspots" (Wakeley 1993). Previous studies of sequence variation in the coding region of the mitochondrial genomes of Australian Aborigines have been restricted to Restriction Fragment Length Polymorphism (RFLP) data (Cann et al. 1987; Stoneking et al. 1990; Huoponen et al. 2001). Analyses based on the information content of the entire mitochondrial genome sequence may provide novel insight into the evolutionary history of Australia.

\section{RESULTS}

\section{Sequence Data}

To study the evolutionary history of the Australian and New Guinean indigenous peoples, we analyzed a total of $101 \mathrm{com}-$ plete mitochondrial genomes from various populations including Australian Aborigines $(n=20$ from Northern Territory populations of Darwin, Alice Springs, Katherine, Tennant Creek, Groote Eylandte) and New Guinean aborigines ( $n=10$ from coastal, $n=11$ from highland), as well as from the peoples of Africa, India, Europe, Asia, Melanesia, and Polynesia $(n=60)$. The Australian samples were selected to represent a broad range of locations within the Northern Territory. The New Guinea samples were selected on the basis of previous mitochondrial typing to represent a wide range of genetic variation within highland and coastal populations. All 101 complete mtDNA sequences are unique and vary in length 


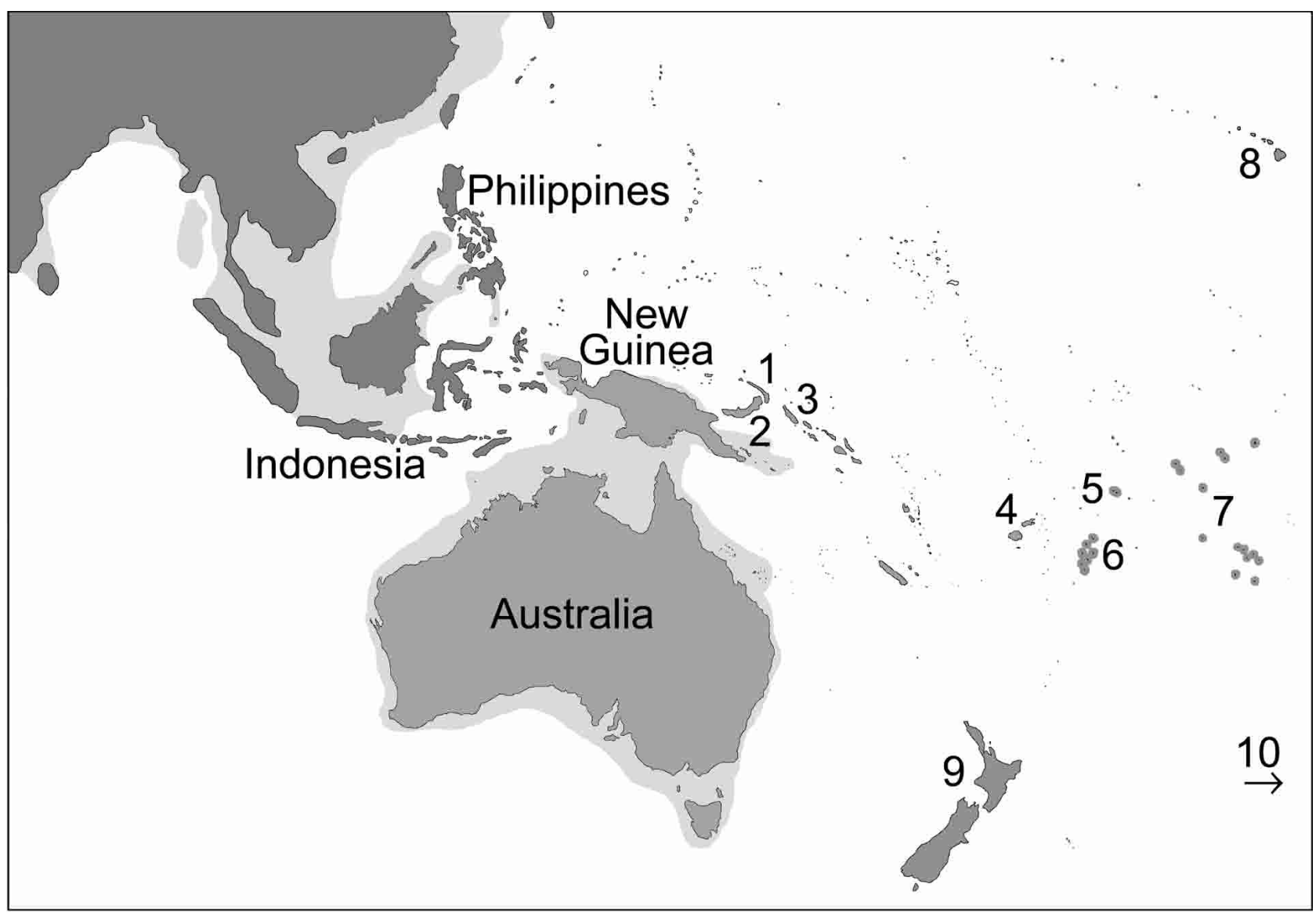

Figure 1 Map of Southeast Asia, Australia, and Melanesia. The predicted extent of late Pleistocene coastline is indicated in light grey. 1, New Ireland; 2, New Britain; 3, Bougainville (Solomon chain); 4, Fiji; 5, Samoa; 6, Tonga; 7, Cook Islands; 8, Hawaiian Islands; 9, New Zealand; 10, Easter Island $(\sim 3,000 \mathrm{~km}$ to the east).

from 16,557-16,575 bp. The 101 complete sequences contain 940 variable sites (741 in the coding region; 199 in the Dloop) of which 438 are parsimony-informative (321 in the coding region; 117 in the D-loop). The mean pairwise distance between complete human mtDNA genomes is $3.18 \times 10^{-3}$ substitutions per site.

\section{Phylogenetic Analysis}

Because the pattern of nucleotide substitution in the mitochondrial D-loop is characterized by a high frequency of homoplasy (Ingman and Gyllensten 2001), we first compared the topology of a neighbor joining (NJ) tree (Saitou and Nei 1987) reconstructed from the 101 complete mitochondrial sequences (tree not shown) with a tree reconstructed using just the coding region sequences (Fig. 2). Although the topologies of the two trees were essentially the same, the tree of sequences with the D-loop removed showed generally higher bootstrap values. For this reason, in studying the phylogenetic relationships among the mitochondrial lineages, we focused solely on the coding region. In the NJ tree, non-African sequences are present on two major branches (Fig. 2, labeled " 1 " and " 2 "). Branch 1 and branch 2 are delineated by the nucleotide positions 8701, 9540, 10398, 10400, 10873, 14783, 15043, and 15301 relative to the Cambridge reference sequence (CRS; Anderson et al. 1981), consistent with what are sometimes referred to as haplogroups $\mathrm{N}$ (branch 1) and $\mathrm{M}$ (branch 2). All but one of the Australian sequences are found on branch 1, together with all European sequences, more than half of the New Guinean sequences, all of the Polynesian sequences, and several Asian sequences. On branch 1 there are several examples where sequences that come from the same geographic region form monophyletic groups, such as a group of sequences predominantly from the New Guinea highlands (Fig. 2, labeled " $1 \mathrm{~b}$ ") and another group comprising the European sequences. Additionally, of the sequences on this branch from the New Guinea coast, all but one cluster with the Polynesian sequences (Fig. 2, labeled " $1 \mathrm{a}$ "). Of the 20 Australian sequences, the 19 that are found on branch 1 are represented on 10 separate subbranches.

Based on an estimated substitution rate for the mitochondrial coding region of $1.7 \times 10^{-8}$ substitutions per site per year (Ingman et al. 2000) and the deepest genetic divergence within branch 1 , the sequences on branch 1 coalesce $71,000 \pm 12,000$ years ago. The coalescence time for sequences on branch 2 is $78,000 \pm 12,000$ years ago.

\section{Mitochondrial Diversity}

Notably, Australia and New Guinea have high nucleotide diversity across the complete mitochondrial genome $\left(\pi=2.26 \times 10^{-3}\right.$ and $2.42 \times 10^{-3}$ respectively) and mean pairwise sequence difference (MPSD) ( $\mathrm{k}=37.4$ and 40.0 respectively), similar to that found across Asia $\left(\pi=2.36 \times 10^{-3}\right.$, 
Downloaded from genome.cshlp.org on April 26, 2023 - Published by Cold Spring Harbor Laboratory Press

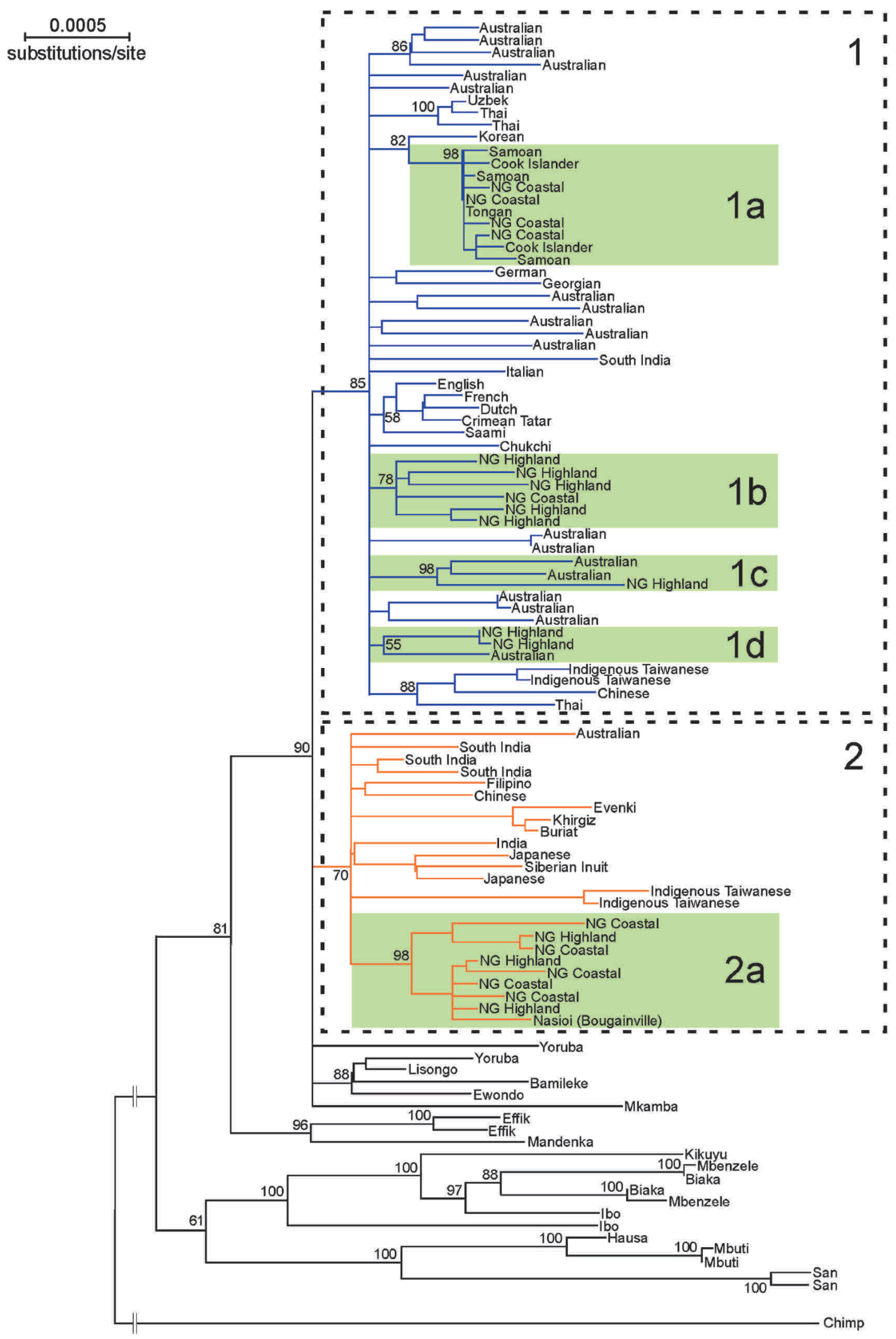

Figure 2 Neighbor-joining (Saitou and Nei 1987) phylogram of 101 mitochondrial coding region sequences using the Kimura two-parameter model for nucleotide substitution. The tree is rooted with a single chimpanzee sequence. Branches of less than $50 \%$ bootstrap support (1000 replicates) are collapsed. Bootstrap values are shown on the nodes. Numbering refers to tree structures discussed in the text. NG, New Guinea. 
$\mathrm{k}=39.0$ ). The variation in the Australian and New Guinean coding region sequences shows a comparable pattern but with nucleotide diversity a little lower than that found across Asia (Table 1). The frequency distribution of pairwise differences for the Australian mtDNA coding region sequences shows a bell-shaped rather than ragged pattern (Fig. 3A), indicating that coalescence events for these sequences occur in a relatively restricted time range which is often associated with population growth (Slatkin and Hudson 1991; Rogers and Harpending 1992). This is a deviation from previously reported mismatch distributions based on D-loop sequences from other hunter gatherer populations, that tend to show a ragged pattern consistent with constant population size (Watson et al. 1996). The pairwise mismatch distribution for the New Guinean sequences shows a more ragged pattern (Fig. 3B). The bimodal distribution could be due to the sequences from the New Guinean population evenly split on branch 1 and branch 2 . In this case, the frequency distribution will reflect that about half of the sequences are separated by the maximum time possible for non-African sequences (Slatkin and Hudson 1991). Tests of selective neutrality based on the number of segregating sites and nucleotide diversity can be used to test whether population sizes have remained stable or have experienced a period of growth (Fu and Li 1989; Tajima 1989). The Australian coding region sequences show evidence of a period of population expansion (Tajima's $\mathrm{D}=-2.23$, $P<0.01 ; \mathrm{Fu}$ and Li's $\mathrm{D}=-2.91, P<0.02$ ), whereas no indication of population expansion is seen among the sequences from New Guinea (Tajima's D $=-1.42, P>0.1$; Fu and Li's $\mathrm{D}=-2.11, P>0.05)$. Sequences from only the New Guinea coast (Tajima's $\mathrm{D}=-0.52, P>0.1 ; \mathrm{Fu}$ and Li's $\mathrm{D}=-1.02$, $P>0.1$ ) and from only the New Guinea highlands (Tajima's $\mathrm{D}=-1.12, P>0.1 ; \mathrm{Fu}$ and Li's $\mathrm{D}=-1.10, P>0.1)$ also show no evidence of expansion.

\section{New Guinea and Polynesia}

The New Guinean sequences are found in three major clades and share two minor clades with Australian Aboriginal sequences. Two of these major clades are present on branch 1 (labeled " $1 \mathrm{a}$ " and " $1 \mathrm{~b}$ ") and are more closely related to the majority of Australian sequences than they are to the New Guinean sequences in the third major clade (Fig. 2, labeled "2a"). Group 1a (Fig. 2) contains sequences from the New Guinea coast and the Polynesian islands of Samoa, Cook Islands, and Tonga. Based on coalescence calculations, these

\begin{tabular}{|c|c|c|c|c|c|c|c|}
\hline & \multicolumn{4}{|c|}{ Complete genome } & \multicolumn{3}{|c|}{ Coding region } \\
\hline & $\mathbf{n}$ & $S$ & $\pi \times 10^{-3}$ & k & $S$ & $\pi \times 10^{-3}$ & k \\
\hline Africa & 21 & 366 & 4.63 & 76.6 & 290 & 3.69 & 57.0 \\
\hline New Guinea & 21 & 207 & 2.42 & 40.0 & 136 & 1.60 & 24.7 \\
\hline Asia & 24 & 269 & 2.36 & 39.0 & 193 & 1.79 & 27.6 \\
\hline Australia & 20 & 265 & 2.26 & 37.4 & 190 & 1.61 & 24.9 \\
\hline Europe & 8 & 81 & 1.49 & 24.7 & 51 & 0.97 & 15.0 \\
\hline
\end{tabular}

The Nasioi sequence and six Polynesian sequences were excluded as they did not conform to the geographic grouping.

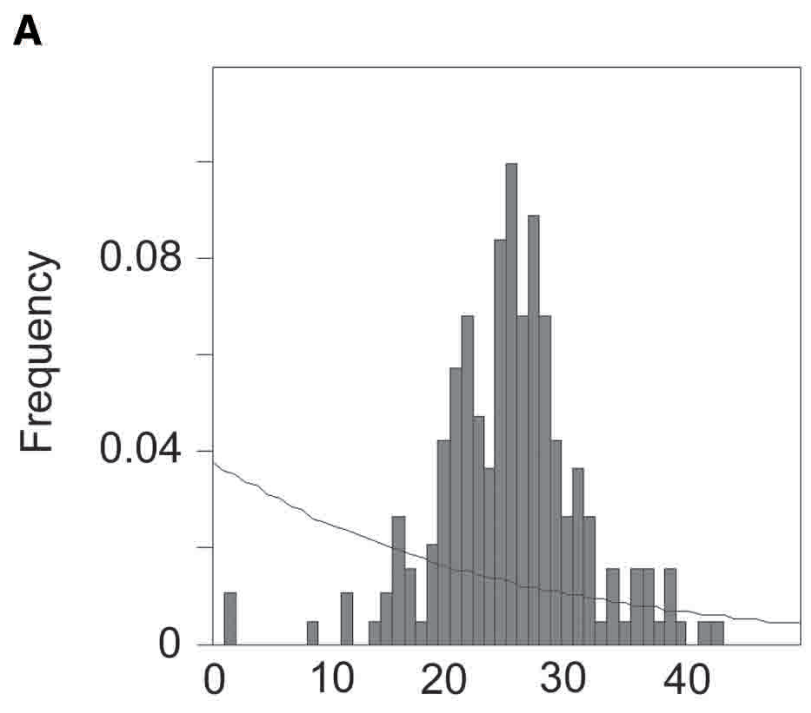

No. Pairwise Differences

B

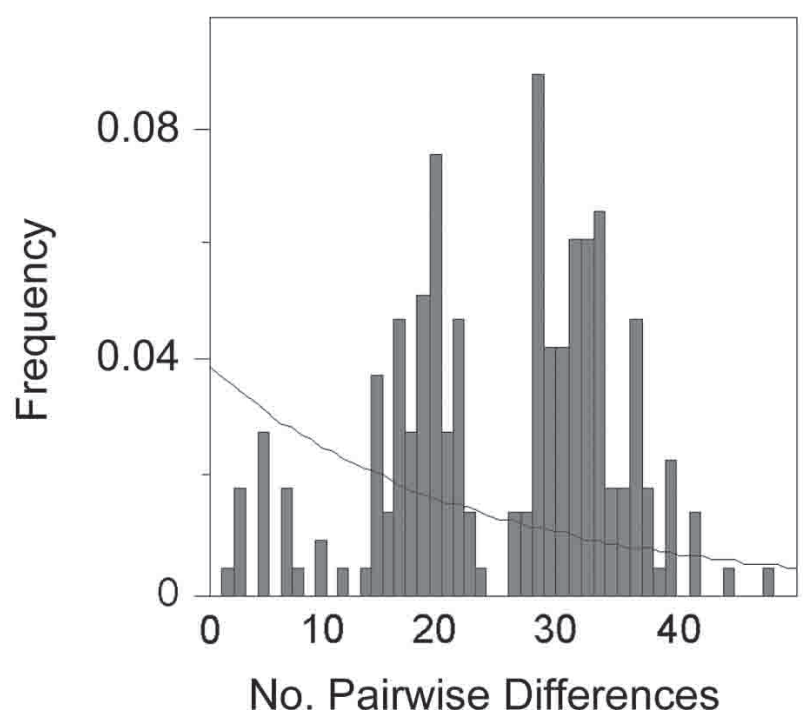

Figure 3 Pairwise mismatch distribution (bars) and the distribution expected under constant population size (line) for Australian coding region sequences $(A)$ and New Guinean coding region sequences $(B)$.

sequences are estimated to have a common ancestor $11,000 \pm 4000$ years ago. In addition to branching support (bootstrap =98), all sequences in group 1a carry a 9-bp deletion. This deletion is also present in the Korean sequence with which the lineages in this group share their evolutionary history. Located in the intergenic region between the COII gene and the Lysine tRNA gene, this deletion has been previously associated with Polynesian and Southeast Asian populations (Redd et al. 1995). Another well supported clade is formed by sequences from both coastal and highland New Guinea and one Nasioi from the Melanesian island of Bougainville (bootstrap $=98$; Fig. 2, labeled " $2 \mathrm{a}$ "). The sequences on this clade coalesce 45,000 \pm 9000 years ago, calculated from the deepest genetic split. Finally, group $1 \mathrm{~b}$ (Fig. 2) consists of sequences 
from both coastal and highland regions of New Guinea, and this group has a coalescence time of $36,000 \pm 8000$ years ago.

\section{Colonization of Sahul}

Most lineages in Australia and New Guinea do not show a relationship indicative of co-colonization or gene flow, but two clades on branch 1 , both of three sequences, contain sequences from both Australia and New Guinea (Fig. 2, marked " $1 \mathrm{c}$ " and " $1 \mathrm{~d}$ "). These groups of sequences last shared common ancestors approximately 46,000 9000 (" $1 \mathrm{c}$ ") and $31,000 \pm 8000$ (" $1 \mathrm{~d}$ ") years ago. Interestingly, in both cases the New Guinean sequences derive from individuals sampled from the highland areas.

Although the number of individuals studied from each location is limited, we also estimated the population divergence in the mitochondrial coding region. The average number of nucleotide differences between populations $\left(\mathrm{d}_{\mathrm{xy}}\right)$ indicates that on average the sequences from New Guinea are somewhat more closely related to those from Australia $\left(\mathrm{d}_{\mathrm{xy}}=\right.$ $0.00175 \pm 0.00015)$ than either of these populations are to the Asian sequences $\left(\mathrm{d}_{\mathrm{xy}}=0.00183 \pm 0.00014, P<0.01\right)$ and $\mathrm{d}_{\mathrm{xy}}=0.00189 \pm 0.00015, P<0.01$, respectively). Also, the sequences from the New Guinea highlands are on average more closely related to the Australian sequences than those from the New Guinea coast $\left(\mathrm{d}_{\mathrm{xy}}=0.00170 \pm 0.00018\right.$ and $\mathrm{d}_{\mathrm{xy}}=$ $0.00181 \pm 0.00022$, respectively $P<0.01$ ).

\section{DISCUSSION}

\section{High Mitochondrial Genome Diversity}

Our study of complete mitochondrial genomes reveals high diversity within Australian and New Guinean populations. This is consistent with analyses that previously reported on diversity in the mitochondrial D-loop of Australian Aborigine and New Guinea highland populations. A study of HVS1 found that Australian Aborigines from a riverine population tend to have higher MPSD than that of the African !Kung population (van Holst Pellekaan et al. 1998). Another analysis of mitochondrial D-loop sequences also reported high nucleotide diversity in Australia, but lower than the values found in Asian and New Guinea highland populations (Redd and Stoneking 1999). High nucleotide diversity, paraphyletic tree topology, and a bell-shaped mismatch distribution are indicators of a large number of singleton-nucleotide differences between sequences, which is often attributed to exponential population growth in a panmictic population (Slatkin and Hudson 1991). The time at which the populations expanded can be estimated from the data. An estimate of Tau $(\tau=20.849)$ for the Australian sequences corresponds to a population expansion about 40,000 years ago. However, if the sequences to be compared are drawn from unrelated populations, the distribution of pairwise differences can mimic the expected distribution under population expansion. Consequently, the pattern of sequence differences among the Australian mitochondrial lineages could also reflect that they have been subdivided into a number of groups. This may be the result of isolation before, or soon after, their arrival in Sahul. Genetic isolation of tribal groups corroborates a conclusion based on analyses of mitochondrial DNA variation in an Aboriginal Australian population from the Northern Territory (Huoponen et al. 2001). Effective population size of the Australian Aboriginal population may have been reduced by an imbalanced male/female ratio ranging from 1.3-2.6 (Birdsell 1993). With a small effective population size, genetic drift would be of substantial influence within the tribe. Also, the great majority of marriages were contracted within the tribe, making the tribe an essentially endogamous genetic unit (Birdsell 1993). The proposed genetic separation among Aboriginal populations could have occurred after a single large population movement to Australia or as the result of multiple migrations over the course of generations from a heterogeneous source population.

\section{Contrasting History of Australian Mitochondrial DNA and Y-Chromosomes}

Our analysis shows a striking difference between the genetic history of females and the reported history of males in the Australian Aboriginal population. As noted previously, the mitochondrial diversity in Australia is relatively high. The pattern seen in the Y-chromosome is different in that an Australia-specific haplotype (DYS390.1del/RPS4Y711T) is found in about $50 \%$ of males in Australia (Kayser et al. 2001; Redd et al. 2002). Relatively high genetic diversity for the mitochondrial genome can be attributed to a high substitution rate (Brown et al. 1979) and to the predominance of patrilocality in human populations (Burton et al. 1996; Seielstad et al. 1998; Oota et al. 2001). In addition, although polygyny was not the norm in Australian aborigines, around 15\% of males in the desert areas, and a higher percentage on Australia's northern coast, have been reported to have multiple wives (Birdsell 1993), further reducing the number of Ychromosomes in the population. However, the smaller effective population size among females would allow genetic drift to act strongly within tribes, homogenizing the tribal mitochondrial gene pool. Therefore, the high mitochondrial diversity noted in the present study could be due to our sampling across subpopulations rather than within a single tribe. Kayser et al. (2001) proposed that the high frequency of a unique haplotype in Australia is the result of a population expansion that started from a few hundred individuals. In this case, the predominance of a unique Y-chromosome haplotype in Australia would be the result of a founder effect. However, there does not appear to be a corresponding loss of genetic diversity resulting from a bottleneck seen among mitochondrial lineages.

\section{Polynesian and Melanesian Lineages}

The number of individuals included in this study from Polynesian and Melanesian populations is not sufficient to address the genetic history of these populations in any detail. However, the position of certain lineages or groups in the phylogenetic tree is interesting in relation to previous propositions regarding these populations. For instance, we note that group 1a contains sequences from the New Guinea coast as well as from the Polynesian islands of Samoa, Cook Islands, and Tonga. About 6000 years ago, an expansion among Neolithic farmers in southern China and Taiwan brought the Austronesian group of languages south and east to New Guinea. During the last 3000-4000 years, these Austronesian speakers have subsequently dispersed throughout the Pacific; first to Fiji, then to Tonga and Samoa, and finally to the Hawaiian Islands, Easter Island, and New Zealand (Fig. 1; Bellwood 1978a, 1991). The timeframe for this colonization has been dated from the spread of Lapita pottery from Melanesia to Polynesia (Bellwood 1978b; Diamond 1988). We note that the sequence composition of group $1 \mathrm{a}$ and the estimated time to

\section{Genome Research}


its common ancestor roughly fits with both the timeframe and population history of this migration.

\section{Relationship Between Australian and New Guinean Mitochondrial Lineages}

Because genetic divergence precedes population divergence, the coalescence date for branch 1 indicates that modern humans must have arrived on the Australian continent less than 70,000 years ago. Also, we would expect that Australia was colonized prior to the time of the expansion of Australian lineages at 40,000 years ago. Although these time estimates are approximate, we note that they are in general agreement with thermoluminescence dates of 50,000-60,000 years ago from two human occupation sites in northern Australia (Roberts et al. 1990, 1994) and one in the southeastern region of Australia (Thorne et al. 1999; Bowler et al. 2003), and by animal extinctions across the continent about 46,000 years ago (Roberts et al. 2001).

Archaeological evidence indicates that humans were present in New Guinea at least 40,000 years ago (Groube et al. 1986), at which time it was still joined with Australia. Our data show that some Australian sequences do share a closer ancestry with some New Guinean sequences than they do with other sequences on branch 1 . In addition, $\mathrm{d}_{\mathrm{xy}}$ distances indicate that New Guinean and Australian sequences are more closely related to each other than either are to the Asian sequences. This may suggest that Australia and New Guinea were colonized jointly or that, if not, these populations have admixed since colonization. Previous studies have yielded differing results with respect to the question of a common genetic origin of these populations. Joint colonization is suggested by a study of mitochondrial D-loop sequence variation (van Holst Pellekaan et al. 1998), mitochondrial RFLP data (Huoponen et al. 2001), and an analysis of $\alpha$-globulin haplotypes (Roberts-Thomson et al. 1996). Other analyses of mitochondrial D-loop sequences (Redd and Stoneking 1999), mitochondrial RFLP data (Stoneking et al. 1990), and Ychromosome data (Kayser et al. 2001) have suggested separate origins for the Australian and New Guinean indigenous peoples. Our mitochondrial data imply that some lineages from the populations of Australia and New Guinea have shared a common history since the initial colonization of Sahul. This is compatible with alternative scenarios involving either a common colonization of both areas from a heterogeneous source population or independent colonization events and subsequent gene flow. The comparison between the mitochondrial and Y-chromosome data in some of the other populations examined is also of interest. The possibility of multiple migrations to New Guinea, as indicated by the mitochondrial data, may also explain the presence of Ychromosome haplotypes in Melanesian populations that are absent in Australia (Kayser et al. 2001). The lack of a common Y-chromosome haplotype found both in Australia and in the New Guinea highlands (or in any other Melanesian population) argues against the concept that the New Guinean and Australian populations are derived from the same migration event (Kayser et al. 2001). However, the Australia-specific Ychromosome haplotype could have arisen after the colonization of Sahul and therefore is absent in other populations.

The overall distant relationship between mitochondrial sequences contributes to the difficulty in decisively resolving the evolutionary history of the Australian and New Guinean highland populations. The observed contemporary genetic differences between the Australian and New Guinean populations may also be compounded by the action of a combination of genetic drift, selection, and complex population movements. An extended investigation of mitochondrial genome diversity in other regions of Australia as well as other populations in the region, based on a larger number of individuals, may provide a better understanding of the genetic history of these populations. For instance, a genetic similarity has been noted between Australian Aborigines and individuals from the Indian Subcontinent based on Y-chromosome (Redd et al. 2002), mitochondrial D-loop (Redd and Stoneking 1999), and phenotypic (Birdsell 1993) data. Our mitochondrial data show no clear similarity between Australian Aborigines and the three southern Indian sequences examined, although a detailed examination of this hypothesis would require the analysis of additional individuals from the Indian Subcontinent. Nevertheless, mitochondrial DNA only provides information on the genetic history of females, and given the contrast between the mitochondrial DNA and the Ychromosome patterns, it appears that additional studies of autosomal loci are also necessary to obtain a balanced view of the evolutionary history of the peoples in this region.

\section{METHODS}

\section{PCR Primers and Sequencing}

The primers used for PCR amplification were as described (Rieder et al. 1998). Sequencing was performed on the PCR products directly using BigDye Primer (Applied Biosystems) chemistry. Separation of sequencing ladders was performed on an ABI 3700 instrument. Both forward and reverse strands were sequenced. Sequence analysis was performed using Sequencing Analysis 3.6.1 (Applied Biosystems), and sequence alignment was made with Sequencher 4.1.2 (Gene Codes). For a detailed description of complete mitochondrial genome sequencing methods, see Ingman and Gyllensten (2001).

\section{Genetic Analysis}

Genetic distances between sequences were calculated by MEGA version 2.1 (Kumar et al. 2001) using the Kimura twoparameter model for nucleotide substitution (Kimura 1980). Phylogenetic trees were reconstructed with Paup4.0b10 (Sinauer Associates). Estimations of genetic diversity and tests for selective neutrality were performed with DnaSP version 3.53 (Rozas and Rozas 1999). Estimations of mean genetic distance between populations were made by DnaSP version 3.53 (Rozas and Rozas 1999) using Jukes and Cantor's substitution model (Jukes and Cantor 1969). To compare the between-population distances, we employed a Mann-Whitney test to analyze pairwise distance data obtained using Paup4.0b10 using the Kimura two-parameter model for nucleotide substitution.

\section{Accession Numbers}

The chimpanzee sequence (Accession no. D38113) we used as an outgroup was obtained from GenBank, as were 49 complete human mitochondrial sequences generated for one of our previous studies (Ingman et al. 2000; Accession nos. AF346963-AF346983, AF346985-AF347000, AF347002AF347011, AF347014-AF347015). The remaining 52 sequences were sequenced for this study and are deposited in GenBank (Accession nos. AY289051-AY289102). All sequences are also available at http://www.genpat.uu.se/mtDB. 


\section{ACKNOWLEDGMENTS}

We thank M. Stoneking and J. Kuhl for DNA samples, and M. Stoneking and J. Kijas for valuable comments on an earlier version of this manuscript. This research was supported by a grant from the Swedish Natural Sciences Research Council.

The publication costs of this article were defrayed in part by payment of page charges. This article must therefore be hereby marked "advertisement" in accordance with 18 USC section 1734 solely to indicate this fact.

\section{REFERENCES}

Anderson, S., Bankier, A.T., Barrell, B.G., de Bruijn, M.H., Coulson, A.R., Drouin, J., Eperon, I.C., Nierlich, D.P., Roe, B.A., Sanger, F., et al. 1981. Sequence and organization of the human mitochondrial genome. Nature 290: 457-465.

Bellwood, P. 1978a. Man's conquest of the Pacific: The prehistory of Southeast Asia and Oceania. Oxford University Press, New York.

Bellwood, P. 1978b. The Polynesians: Prehistory of an island people. Thames and Hudson Ltd., London.

Bellwood, P. 1991. The Austronesian dispersal and the origin of languages. Sci. Am. 265: 70-75.

Birdsell, J.B. 1993. Microevolutionary patterns in Aboriginal Australia: A gradient analysis of clines. Oxford University Press, New York.

Bowler, J.M., Johnston, H., Olley, J.M., Prescott, J.R., Roberts, R.G., Shawcross, W., and Spooner, N.A. 2003. New ages for human occupation and climatic change at Lake Mungo, Australia. Nature 421: $837-840$.

Brown, W.M., George Jr., M., and Wilson, A.C. 1979. Rapid evolution of animal mitochondrial DNA. Proc. Natl. Acad. Sci. 76: 1967-1971.

Burton, M.L., Moore, C.C., Whiting, J.W.M., and Romney, A.K. 1996. Regions based on social structure. Curr. Anthropol. 37: 87-123.

Cann, R.L., Stoneking, M., and Wilson, A.C. 1987. Mitochondrial DNA and human evolution. Nature 325: 31-36.

Diamond, J. 1988. Express train to Polynesia. Nature 336: 307-308.

Fu, Y.X. and Li, W.H. 1989. Statistical tests of neutrality of mutations. Genetics 133: 693-709.

Giles, R.E., Blanc, H., Cann, H.M., and Wallace, D.C. 1980. Maternal inheritance of human mitochondrial DNA. Proc. Natl. Acad. Sci. 77: 6715-6719.

Groube, L., Chappell, J., Muke, J., and Price, D. 1986. A 40,000 year-old human occupation site at Huon Peninsula, Papua New Guinea. Nature 324: 453-455.

Huoponen, K., Schurr, T.G., Chen, Y., and Wallace, D.C. 2001 Mitochondrial DNA variation in an aboriginal Australian population: Evidence for genetic isolation and regional differentiation. Hum. Immunol. 62: 954-969.

Ingman, M. and Gyllensten, U. 2001. Analysis of the complete human mtDNA genome: Methodology and inferences for human evolution. J. Hered. 92: 454-461.

Ingman, M., Kaessmann, H., Paabo, S., and Gyllensten, U. 2000. Mitochondrial genome variation and the origin of modern humans. Nature 408: 708-713.

Jukes, T.H. and Cantor, C.R. 1969. Evolution of protein molecules. In Mammalian protein metabolism (ed. H.N. Munro). Academic Press, New York.

Kayser, M., Brauer, S., Weiss, G., Schiefenhovel, W., Underhill, P.A. and Stoneking, M. 2001. Independent histories of human Y chromosomes from Melanesia and Australia. Am. J. Hum. Genet. 68: $173-190$.

Kimura, M. 1980. A simple method for estimating evolutionary rates of base substitutions through comparative studies of nucleotide sequences. J. Mol. Evol. 16: 111-120.

Klein, R.G. 1989. The human career: Human biological and cultural origins. University of Chicago Press, Chicago.

Kumar, S., Tamura, K., Jakobsen, I.B., and Nei, M. 2001. MEGA2: Molecular evolutionary genetics analysis software. Arizona State University, Tempe, AZ.

Olivio, P.D., Van de Walle, M.J., Laipis, P.J., and Hauswirth, W.W. 1983. Nucleotide sequence evidence for rapid genotypic shifts in the bovine mitochondrial DNA D-loop. Nature 306: 400-402.

Oota, H., Settheetham-Ishida, W., Tiwawech, D., Ishida, T., and
Stoneking, M. 2001. Human mtDNA and Y-chromosome variation is correlated with matrilocal versus patrilocal residence. Nat. Genet. 29: 20-21.

Redd, A.J. and Stoneking, M. 1999. Peopling of Sahul: mtDNA variation in aboriginal Australian and Papua New Guinean populations. Am. J. Hum. Genet. 65: 808-828.

Redd, A.J., Takezaki, N., Sherry, S.T., McGarvey, S.T., Sofro, A.S., and Stoneking, M. 1995. Evolutionary history of the COII/tRNALys intergenic 9 base pair deletion in human mitochondrial DNAs from the Pacific. Mol. Biol. Evol. 12: 604-615.

Redd, A.J., Roberts-Thomson, J., Karafet, T., Bamshad, M., Jorde, L.B., Naidu, J.M., Walsh, B., and Hammer, M.F. 2002. Gene flow from the Indian subcontinent to Australia: Evidence from the $\mathrm{Y}$ chromosome. Curr. Biol. 12: 673-677.

Rieder, M.J., Taylor, S.L., Tobe, V.O., and Nickerson, D.A. 1998. Automating the identification of DNA variations using quality-based fluorescence resequencing: Analysis of the human mitochondrial genome. Nucleic Acids Res. 26: 967-973.

Roberts, R.G., Jones, R., and Smith, M.A. 1990. Thermoluminescence dating of a 50,000-year old human occupation site in northern Australia. Nature 345: 153-156.

Roberts, R.G., Jones, R., Spooner, N.A., Head, M.J., Murray, A.S., and Smith. M.A. 1994. The human colonization of Australia: Optical dates of 53,000 and 60,000 years bracket human arrival at Deaf Adder Gorge, Northern Territory. Quaternary Sci. Rev. 13: 575-586.

Roberts, R.G., Flannery, T.F., Ayliffe, L.K., Yoshida, H., Olley, J.M., Prideaux, G.J., Laslett, G.M., Baynes, A., Smith, M.A., Jones, R., et al. 2001. New ages for the last Australian megafauna: Continent-wide extinction about 46,000 years ago. Science 292: $1888-1892$.

Roberts-Thomson, J.M., Martinson, J.J., Norwich, J.T., Harding, R.M., Clegg, J.B., and Boettcher, B. 1996. An ancient common origin of aboriginal Australians and New Guinea highlanders is supported by $\alpha$-globin haplotype analysis. Am. J. Hum. Genet. 58: $1017-1024$

Rogers, A.R. and Harpending, H. 1992. Population growth makes waves in the distribution of pairwise genetic differences. Mol. Biol. Evol. 9: 552-569.

Rozas, J. and Rozas, R. 1999. DnaSP version 3: An integrated program for molecular population genetics and molecular evolution analysis. Bioinformatics 15: 174-175.

Saitou, N. and Nei, M. 1987. The neighbor-joining method: A new method for reconstructing phylogenetic trees. Mol. Biol. Evol. 4: 406-425.

Seielstad, M.T., Minch, E., and Cavalli-Sforza, L.L. 1998. Genetic evidence for a higher female migration rate in humans. Nat. Genet. 20: $278-280$.

Slatkin, M. and Hudson, R.R. 1991. Pairwise comparisons of mitochondrial DNA sequences in stable and exponentially growing populations. Genetics 129: 555-562.

Stoneking, M., Jorde, L.B., Bhatia, K., and Wilson, A.C. 1990. Geographic variation in human mitochondrial DNA from Papua New Guinea. Genetics 124: 717-733.

Tajima, F. 1989. Statistical method for testing the neutral mutation hypothesis by DNA polymorphism. Genetics 123: $585-595$.

Tamura, K. and Nei, M. 1993. Estimation of the number of nucleotide substitutions in the D-loop of mitochondrial DNA in humans and chimpanzees. Mol. Biol. Evol. 10: 512-526.

Thorne, A., Grun, R., Mortimer, G., Spooner, N.A., Simpson, J.J., McCulloch, M., Taylor, L., and Curnoe, D. 1999. Australia's oldest human remains: Age of the Lake Mungo 3 skeleton. $J$ Hum. Evol. 36: 591-612.

van Holst Pellekaan, S., Frommer, M., Sved, J., and Boettcher, B. 1998. Mitochondrial control-region sequence variation in aboriginal Australians. Am. J. Hum. Genet. 62: 435-449.

Wakeley, J. 1993. Substitution rate variation among sites in hypervariable region 1 of human mitochondrial DNA. J. Mol. Evol. 37: 613-623.

Watson, E., Bauer, K., Aman, R., Weiss, G., von Haeseler, A., and Paabo, S. 1996. mtDNA sequence diversity in Africa. Am. J. Hum. Genet. 59: 437-444.

Received August 2, 2002; accepted in revised form April 23, 2003. 


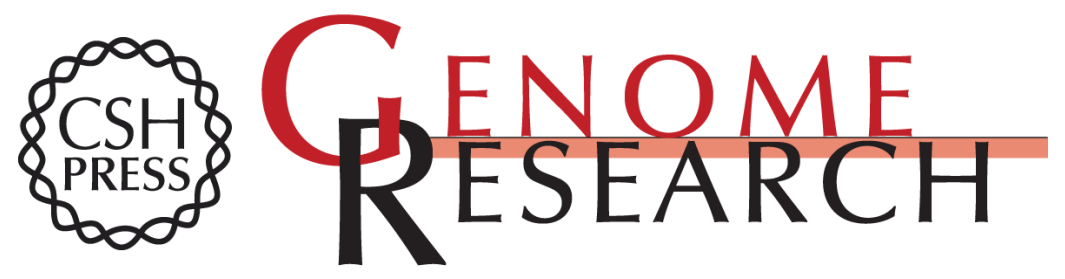

\section{Mitochondrial Genome Variation and Evolutionary History of Australian and New Guinean Aborigines}

Max Ingman and Ulf Gyllensten

Genome Res. 2003 13: 1600-1606

Access the most recent version at doi:10.1101/gr.686603

References This article cites 35 articles, 6 of which can be accessed free at:

http://genome.cshlp.org/content/13/7/1600.full.html\#ref-list-1

\section{License}

Email Alerting Receive free email alerts when new articles cite this article - sign up in the box at the Service top right corner of the article or click here.

\section{Affordable, Accurate Sequencing.}

To subscribe to Genome Research go to:

https://genome.cshlp.org/subscriptions 